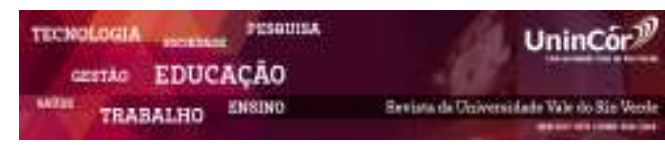

Revista da Universidade Vale do Rio Verde ISSN: 1517-0276 / EISSN: 2236-5362 Vol. 16 | n. 1 | Ano 2018

José Klidenberg de Oliveira Júnior Universidade Federal da Paraíba joseklidemberg@gmail.com

Luiz Eduardo Marinho Vieira

Universidade Estadual da Paraíba luizeduardomv1@gmail.com

Manoela Natacha de Almeida Silva

Pós-graduação em Ortodontia CECAP manoela.natacha@gmail.com

Mariana Gil Gomes de Medeiros Araújo Pós-graduação em Ortodontia COESP gilmarianaodontoufcg@gmail.com

Mayara da Silva Henriques Limeira Universidade Federal de Campina Grande mayaralimeira23@gmail.com

Dayse Hanna Maia Oliveira Universidade Federal de Campina Grande dayse.hmaia@gmail.com

Lucianna Dellamano Chacon Universidade de São Paulo - USP lucianadchacon@gmail.com

Maria Carolina Bandeira Macena Universidade Federal de Campina Grande lcbandeira79@hotmail.com

Rachel de Queiroz Ferreira Rodrigues Universidade Federal de Campina Grande rachelperio@gmail.com

\section{A SAÚdE BUCAL NA PERCEPÇÃO DOS USUÁRIOS DE UM RESTAURANTE POPULAR LOCALIZADO EM UMA CIDADE MÉDIO PORTE DA PARAÍBA}

\section{RESUMO}

A prevenção em odontologia tem tido ênfase ultimamente. Os cuidados com a saúde bucal têm ido além da visão estética. $\mathrm{O}$ presente estudo visa avaliar a autopercepção da saúde bucal dos usuários do Restaurante Popular da Cidade de Patos/PB. Trata-se de um estudo transversal, foi aplicado um questionário com questões abordando variáveis socioeconômicas e sobre saúde bucal. Em seguida os dados foram analisados através do software Statistical Package for the Social Sciences (SPSS) versão 22.0. Foram avaliados 252 usuários por meio dos questionários, uma maior prevalência para o sexo masculino $(56,3 \%)$, com relação ao grau de escolaridade, o que obteve maior frequência foi o ensino médio completo $(30,7 \%)$ seguido do ensino fundamental incompleto (29\%). Com relação à autovaliação da saúde bucal, 49,2 \% classificam como "boa", 28,7\% consideraram sua saúde bucal "regular", 6,3\% dos participantes da pesquisa declararam ter a saúde bucal "ruim". Quando indagados sobre a participação de atividades em promoção de saúde bucal, a maioria dos participantes já participou $(81,9 \%)$ de alguma atividade ao longo da vida. No que diz respeito à frequência de escovação 92,5\% dos usuários marcaram a resposta "duas vezes ou mais por dia", com relação à periodicidade de visitas ao dentista uma parcela de $11 \%$ dos participantes afirmou não ter visitado o dentista há três anos ou mais, outros $2 \%$ falaram nunca ter consultado o dentista. Dessa forma, concluiu-se que os usuários que frequentaram o Restaurante Popular na cidade de Patos-PB fizeram uma avaliação positiva de sua condição bucal.

Palavras-chave: Autopercepção. Saúde Bucal. Saúde Coletiva. Prevenção. Epidemiologia.

\section{THE BUCAL HEALTH IN THE PERCEPTION OF USERS OF A POPULAR RESTAURANT LOCATED IN AN A VERAGE CITY OF PARAÍBA}


"regular" oral health, $6.3 \%$ of the study participants declared their oral health "bad." When asked about the participation of activities in oral health promotion, the majority of participants already participated in some $81.9 \%$ of life activity. Regarding the frequency of toothbrushing, $92.5 \%$ of users scored twice or more per day, with regard to the periodicity of visits to the dentist, a portion of $11 \%$ of the participants stated that they had not visited the dentist three years ago Or more, another $2 \%$ said they had never consulted the dentist. Thus, it was concluded that the users who attended the Popular Restaurant in the city of Patos-PB made a positive evaluation of their oral condition.

Keywords: Self Concept. Oral Health. Public Health. Prevention. Epidemiology.

Recebido em: 17/12/2017 - Aprovado em: 10/02/2018 - Disponibilizado em: 15/07/2018

\section{INTRODUÇÃO}

A alimentação com valores nutricionais adequados é um direito fundamental que confere a dignidade do ser humano. Segundo a Constituição Federal de 1988, todos os cidadãos têm direito ao acesso a alimentação de forma igualitária e com valores nutricionais justos (ARAÚJO; ALMEIDA; BASTOS, 2007).

O Programa de Restaurantes Populares (PRP) surge como uma política pública pautada pelo governo, que visa diminuir/erradicar a fome e a exclusão do indivíduo em um contexto de expansão da cidadania no ambiente público democrático (GOBATO; PANIGASSI; VILLALBA, 2012).

O Restaurante Popular da cidade de Patos na Paraíba serve em média diariamente 600 refeições, essas refeições são servidas desde crianças, adultos, pessoas portadoras de deficiências e idosos. Como se trata de um grande grupo concentrado em único local, é interessante a implantação de medidas preventivas em diversos campos da saúde, no caso do projeto em questão, relacionamos temas sobre a saúde bucal.

É sabido que a cárie e a doença periodontal constituem um importante problema de saúde bucal pública no Brasil, como demonstrado no levantamento epidemiológico realizado pelo Ministério da Saúde em 2010. Diversos estudos têm comprovado a possibilidade de prevenção e controle das doenças bucais que ocorrem devido à placa, através da modificação de seus fatores etiológicos. No que diz respeito à cárie, as medidas preconizadas para sua prevenção baseiam-se, fundamentalmente, na educação e motivação do paciente ou população em relação à desorganização da placa bacteriana, à restrição do consumo do açúcar e ao uso do flúor (GAIÃO; ALMEIDA; HEUKELBACH, 2006).

A prevenção em odontologia tem tido ênfase ultimamente. Os cuidados com a saúde bucal têm ido além da visão estética. No novo paradigma de saúde, se desperta uma maior consciência sobre a necessidade de se manter uma saúde bucal satisfatória que, por sua vez, é refletida na saúde geral (AQUILANTE et al, 2003). 
Os profissionais da saúde têm a responsabilidade de atuar na prevenção de doenças, minimizando riscos e promovendo condições favoráveis para que se torne possível alcançar e manter a saúde bucal. Por outro lado, os pacientes também precisam ser conscientizados sobre o seu papel nos cuidados com a saúde (SANTOS; RODRIGUES; GARCIA, 2010).

É por isso que a odontologia moderna tem se comprometido cada vez mais com o aspecto preventivo das patologias e afecções bucais através de campanhas e estudo de prevalências que mostram a situação social. Na odontologia tradicional imperante por décadas, buscava-se apenas a face curativa de toda a problemática da saúde bucal do paciente, sabe-se atualmente que isto foi resultado de uma formação acadêmica descompromissada com a preservação e manutenção da saúde bucal da população (MOURA et al., 2010).

Sendo assim, objetivo do presente estudo é avaliar a autopercepção da saúde bucal dos usuários do Restaurante Popular da Cidade de Patos localizada no interior do estado da Paraíba, de modo a traçar o perfil de saúde bucal desses usuários subsidiando dados suficientes para o desenvolvimento de atividades interceptativas/educativas visando à melhoria da higiene bucal diária após a alimentação e proporcionando o controle da placa bacteriana de modo a prevenir doenças bucais mais prevalentes da cavidade oral (cárie dentária e doença periodontal).

\section{MATERIAL E MÉTODO}

Trata-se de um estudo transversal, composto por usuários do Restaurante Popular que é o campo empírico desta investigação. A referida cidade está situada no município de Patos/PB, que é uma das cinco mais populosos municípios do estado Paraíba. Localizada na mesorregião do Sertão Paraibano, distante a 307 km de João Pessoa, sua sede concentra-se no centro do estado com vetores viários interligando-o com toda a Paraíba e viabilizando o acesso aos Estados do Rio Grande do Norte, Pernambuco e Ceará. De acordo com o IBGE (Instituto Brasileiro de Geografia e Estatística), no ano de 2016 sua população foi estimada em 107.067 habitantes.

Para realização do estudo utilizou-se o método indutivo e procedimento comparativo, estatístico-descritivo, através da técnica de documentação direta extensiva através do questionário (LAKATOS; MARCONI, 2003). O estudo procedeu-se com usuários que aguardavam a refeição na fila do Restaurante Popular.

Previamente a aplicação do questionário foi realizada um estudo piloto com 15 usuários $(n=15)$ com a finalidade de verificar se o formulário apresentava fidedignidade (qualquer pessoa que o aplique obterá sempre os mesmos resultados), validade (os dados recolhidos são necessários à pesquisa) e operatividade (vocabulário acessível e significado claro). O estudo piloto não indicou prováveis alterações no instrumento da pesquisa.

O questionário de autoavaliação da saúde bucal com tradução transcultural do Perfil do Impacto da Saúde Bucal - OHIP (The Oral Health Impact Profile) - Bortoli, 2003, outro questionário utilizado como base foi $\mathrm{o}$ de conhecimento sobre saúde bucal Pinheiro et al., 2005 ambos estudos já publicado para obtenção de informações sobre saúde bucal. 
O cálculo amostral foi realizado método de conveniência, tendo uma magnitude de efeito alta $(0,8)$ de acordo com o ranqueamento de Cohen (1988), escore $\mathrm{Z}$ tipo I $(1,64)$ unicaudal, gerando um poder de $80 \%$. Dessa forma, resultouse um tamanho amostral de $252 \quad(n=252)$, considerando um $p$ estatisticamente significativo $(p=0,05)$.

O formulário foi elaborado com 17 questões de múltipla escolha e subjetivas. Este número foi determinado procurando-se selecionar assuntos mais significativos uma vez que os usuários estavam em seu horário de almoço e não disponibilizariam muito tempo para responder ao documento em questão.

Em seguida procedeu-se a aplicação dos formulários por pesquisadores treinados a fim de suprir supostas dúvidas sem influenciar nas respostas. Foram obtidos 252 questionários $(n=252)$ referentes aos quatros cursos analisados, dentre as variáveis verificadas encontram-se dados socioeconômicos (gênero e faixa etária) e questões relativas à saúde bucal (avaliação da saúde bucal, visitas ao dentista, escovação, problemas relacionados à mastigação, utilização do fio dental entre outras).

O projeto foi apreciado pelo Comitê de Ética em Pesquisa do Hospital Universitário
Alcides Carneiro / UFCG e aprovado sob o número: 35450214.6.0000.5182

Os dados foram analisados através do software Statistical Package for the Social Sciences (SPSS) versão 22.0.

\section{RESULTADOS E DISCUSSÃO}

Foram avaliados 252 usuários por meio dos questionários, analisando os dados socioeconômicos do estudo, observou-se uma maior prevalência para o sexo masculino $(56,3 \%)$, com relação ao grau de escolaridade, o que obteve maior frequência foi o ensino médio completo seguido do ensino fundamental incompleto. Ainda analisou-se o grupo etário com maior frequência, entre os entrevistados, foi o de 18 e 25 anos (46,1\%), seguido da faixa etária dos 26-35 anos (28\%) e com menor frequência encontra-se a faixa etária dos 56 a 65 anos (4\%). (Tabela 1). 
Tabela 1- Distribuição da frequência da variável socioeconômico gênero, escolaridade e faixa etária.

\begin{tabular}{|c|c|c|c|}
\hline \multirow[t]{2}{*}{ VARIÁVEL } & & \multicolumn{2}{|c|}{ FREQUÊNCIA } \\
\hline & & $n$ & $\%$ \\
\hline GÊNERO & $\begin{array}{c}\text { Feminino } \\
\text { Masculino } \\
\text { Total } \\
\end{array}$ & $\begin{array}{l}111 \\
141 \\
\mathbf{2 5 2} \\
\end{array}$ & $\begin{array}{l}43,7 \% \\
56,3 \% \\
\mathbf{1 0 0 \%} \\
\end{array}$ \\
\hline \multirow{6}{*}{ ESCOLARIDADE } & $\begin{array}{l}\text { Ens. Fundamental } \\
\text { Incompleto }\end{array}$ & 53 & $20,9 \%$ \\
\hline & $\begin{array}{l}\text { Ens. Fundamental } \\
\text { Completo } \\
\text { Ensino Médio } \\
\text { Incompleto }\end{array}$ & 19 & $7,5 \%$ \\
\hline & $\begin{array}{c}\text { Ensino Médio } \\
\text { Completo }\end{array}$ & 46 & $18,1 \%$ \\
\hline & Ensino Superior & 78 & $30,7 \%$ \\
\hline & & 56 & $22 \%$ \\
\hline & Total & 252 & $100 \%$ \\
\hline \multirow{7}{*}{ FAIXA ETÁRIA } & $18-25$ anos & 117 & $46,1 \%$ \\
\hline & 26-35 anos & 71 & $28,0 \%$ \\
\hline & $36-45$ anos & 38 & $15,0 \%$ \\
\hline & 46-55 anos & 21 & $8,3 \%$ \\
\hline & $56-65$ anos & 1 & $0,4 \%$ \\
\hline & $66-75$ anos & 4 & $1,6 \%$ \\
\hline & Total & 252 & $100 \%$ \\
\hline
\end{tabular}

Com relação à autovaliação da saúde bucal, 49,2 \% $(n=124)$ classificam como "boa", 28,7\% $(n=72)$ consideraram sua saúde bucal "regular" $16(6,3 \%)$ participantes da pesquisa declararam ter a saúde bucal ruim (Tabela 2).

Quando indagados sobre a participação de atividades em promoção de saúde bucal, a maioria dos participantes já participou de alguma atividade ao longo da vida $81,9 \%(n=208)$. Em relação à frequência escovação 92,5\% $(n=235)$ a resposta "duas vezes ou mais por dia" foi a que obteve maior índice estatístico (Tabela 2).

Vale ressaltar que dentro da amostra estudada uma parcela de $2,8 \%(n=5)$ relatou não fazer nenhum tipo de higienização justificando a falta de dentes. Quando interrogados sobre a última visita ao dentista $66,9 \% \quad(\mathrm{n}=170)$ responderam que foram ao dentista há menos de um ano. 
Tabela 2 - Distribuição da frequência absoluta dos itens relacionados aos cuidados e autoavaliação da saúde bucal dos usuários do Restaurante Popular

\begin{tabular}{|c|c|c|c|c|c|}
\hline \multirow[t]{2}{*}{ VARIÁVEL } & & \multicolumn{2}{|c|}{$\begin{array}{l}\text { FREQUÊNCIA } \\
\text { fi } / \%\end{array}$} & \multirow[t]{2}{*}{$\overline{\mathbf{x}}$} & \multirow[t]{2}{*}{$\sigma$} \\
\hline & & $n$ & $\%$ & & \\
\hline \multirow{7}{*}{$\begin{array}{l}\text { AVALIAÇÃO DA } \\
\text { SAÚDE BUCAL }\end{array}$} & Ótima & 28 & $11 \%$ & \multirow{7}{*}{1,79} & \multirow{7}{*}{1,924} \\
\hline & Boa & 124 & $49,2 \%$ & & \\
\hline & Regular & 72 & $28,7 \%$ & & \\
\hline & Péssima & 7 & $2,8 \%$ & & \\
\hline & Ruim & 16 & $6,3 \%$ & & \\
\hline & Não sabe & 5 & $2 \%$ & & \\
\hline & Total & 252 & $100 \%$ & & \\
\hline \multirow{3}{*}{$\begin{array}{l}\text { ORIENTAÇÃO DE } \\
\text { SAÚDE BUCAL }\end{array}$} & $\mathrm{Sim}$ & 208 & $81,9 \%$ & \multirow[t]{3}{*}{0,17} & \multirow[t]{3}{*}{0,38} \\
\hline & Não & 44 & $17,3 \%$ & & \\
\hline & Total & 252 & $100 \%$ & & \\
\hline \multirow{5}{*}{$\begin{array}{l}\text { FREQUÊNCIA DE } \\
\text { ESCOVAÇÃO }\end{array}$} & Não escovo todos & 5 & $2,8 \%$ & \multirow{5}{*}{2,91} & \multirow{5}{*}{3,46} \\
\hline & os dias & & 470 & & \\
\hline & $\begin{array}{l}\text { Uma vez ao dia } \\
\text { Duas vezes ou }\end{array}$ & $\begin{array}{c}12 \\
235\end{array}$ & $\begin{array}{l}4,1 \% \\
92,5 \%\end{array}$ & & \\
\hline & mais por dia & & & & \\
\hline & Total & 252 & $100 \%$ & & \\
\hline \multirow{7}{*}{$\begin{array}{c}\text { ÚLTIMA CONSULTA } \\
\text { AO DENTISTA }\end{array}$} & $\begin{array}{l}\text { Há menos de um } \\
\text { ano }\end{array}$ & 170 & $66,9 \%$ & \multirow{7}{*}{0,67} & \multirow{7}{*}{1,124} \\
\hline & Entre dois e menos & 49 & $12,6 \%$ & & \\
\hline & de três anos & & & & \\
\hline & $\begin{array}{l}\text { Há três anos ou } \\
\text { mais }\end{array}$ & 28 & $11,0 \%$ & & \\
\hline & \multirow{3}{*}{$\begin{array}{c}\text { consultou } \\
\text { Total }\end{array}$} & 5 & $2 \%$ & & \\
\hline & & & & & \\
\hline & & 252 & $100 \%$ & & \\
\hline
\end{tabular}

n, número da amostra; fi,frequência total; $\bar{x}$, média; $\sigma$, desvio-padrão

Uma parcela de $11 \%$ dos participantes afirmou não ter visitado o dentista há três anos ou mais, outros $2 \%$ falaram nunca ter consultado o dentista. Quando pesquisado o motivo daqueles que fizeram a visita ao dentista há menos de um ano, $45 \%$ responderam que o objetivo de revisão, manutenção ou prevenção, outros $30,3 \%$ afirmaram que procuraram o profissional para a realização de obturação, $15 \%$ afirmaram ter procurado o cirurgião-dentista para realização extração dentária (Gráfico 1). 
Gráfico 1 - Procedimento procurado pelos usuários no último ano

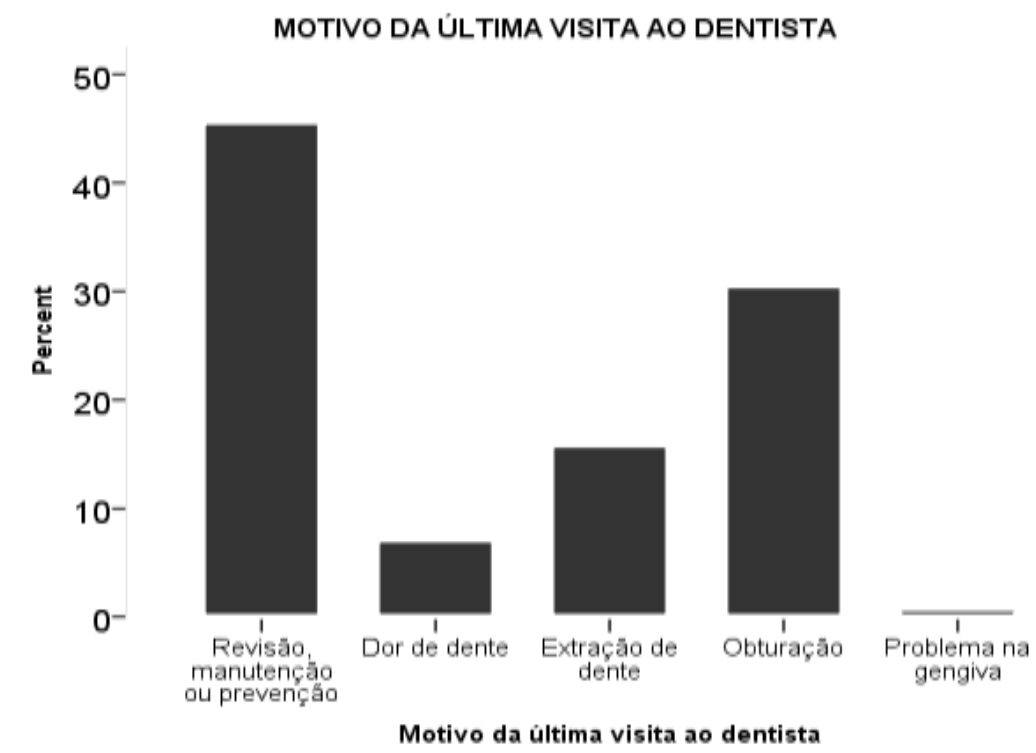

Uma das principais vertentes da odontologia contemporânea é promover a promoção de saúde bucal, essa por sua vez tem o objetivo de projetar o individuo como o próprio provedor da sua saúde através de intervenções no campo da educação possibilitando que o indivíduo amplie o entendimento sobre saúde, isso facilita $\mathrm{o}$ processo de aplicação dos conceitos de saúde na comunidade aumentando a sua habilidade de resolver seus próprios problemas com competência (CARVALHO et al., 2016).

As atividades de promoção em saúde podem ser desenvolvidas em diversos setores com os variados grupos, como escolas, creches ou até mesmo em restaurantes populares, devido o fluxo contínuo de pessoas, atingindo diversos públicos, permitindo a expansão e $\mathrm{o}$ embasamento da saúde através de um trabalho coletivo e participativo com toda a comunidade (SANTOS et al., 2016).
$\mathrm{Na}$ maioria das vezes o processo de avaliação dos grupos rejeita os fatores socioeconômicos e culturais, realizando o planejamento dos serviços da saúde bucal considerando apenas necessidades emergenciais, pois se enquadra dentro de um modelo caracterizado na identificação de doenças deixando passar a forma com que o indivíduo pensa a respeito sobre a autopercepção frente ao processo saúde-doença (SANTOS et al., 2007).

Para tanto é necessário entender como o indivíduo percebe sua saúde bucal, pois estudos mostram que a autopercepção está relacionada a alguns fatores clínicos, como a saúde gengival, dentes cariados, perdidos ou restaurados e ainda fatores como a classe social, idade, renda e sexo (TEXEIRA et al., 2014)

No presente estudo, a caracterização social da amostra estudada mostrou uma população jovem, média de 23 anos de idade, com 8,6 anos de estudo, em média, o que evidência que, pelo menos, o ensino médio foi 
completado. As classes sociais predominantes foram o proletariado típico e o proletariado nãotípico, que corresponde a uma situação onde o indivíduo, sem possuir curso superior, vende sua mão de obra em troca de um salário, provavelmente apresentava necessidades básicas não satisfeitas em vários setores, sendo um deles a saúde bucal.

Torna-se relevante analisar esses indivíduos segundo sua classe social, pois as doenças que afetam os indivíduos não podem ser explicadas apenas pelos determinantes biológicos que o caracterizam, uma vez que a qualidade de vida é influenciada pelos aspectos sociais, econômicos, políticos e culturais de uma sociedade (TEXEIRA et al., 2014)

Quanto a percepção sobre saúde bucal, a maioria dos indivíduos fez uma avaliação positiva, classificando como sua saúde bucal como "boa" $(49,2 \%)$, esses dados convergem para o estudo de Araújo et al. (2007), onde a amostra relatou um percentual elevado com relação à autopercepção da saúde bucal como boa, correspondente a adolescentes, adultos e idosos $(68,8 \%, \quad 58,1 \%$ e $66,3 \%)$. Dados parecidos foram descritos por Baldani et al. (2010) em seu estudo com idosos, 69\% do idosos entrevistados consideram sua saúde bucal boa ou muito boa apesar de $76 \%$ utilizarem prótese total.

Entre os entrevistados, $66,9 \%$ costumam ir ao dentista de forma regular ir, e 81,9\% dos indivíduos entrevistados afirmou ter recebido alguma orientação de saúde bucal por um profissional. Dados semelhantes são descritos Pinheiro et al. (2005) que $86 \%$ dos entrevistados, responderam que costumavam ir ao cirurgião dentista e que já receberam alguma vez a orientação destes profissionais quanto à higiene bucal, comprovando a importância do profissional de odontologia.

A escovação é um processo mecânico importante do indivíduo frente ao biofilme dental e a gengivite (BUSATO et al., 2015). Tal fato foi documentado nos estudos clássicos de Löe et al (1965), onde a interrupção da escovação dental resultou em rápido acúmulo do biofilme dental e desenvolvimento de gengivite num período de três semanas. No presente estudo 92,5\% afirmaram escovar duas vezes ou mais por dia, esses dados corroboram com estudos encontrados na literatura, em que um dos questionamentos avaliados na pesquisa, estava à frequência de escovação, e os resultados demonstraram que $45 \%$ da amostra realizava o procedimento três vezes ao dia (ABEGG, 1997, OLYMPIO; BARDAL, 2006)

Apesar do presente estudo não tenha sido feito o exame clínico nos usuários do restaurante popular e, dessa forma, não seja possível comparar os dados subjetivos explicitados pelos participantes com a situação clínicas dos usuários, estudos sobre autopercepção já mostraram que a maioria das pessoas classifica sua condição bucal de maneira favorável mesmo com situações clínicas incompatíveis. Uma justificativa para este fato é porque as medidas adotadas utilizadas pelo profissional são intervencionistas e com pontos fracos que mensure a percepção de saúde bucal das pessoas. Os achados literários mostraram que existe relação entre a percepção da condição bucal e algumas variáveis clínicas, mas que essa 
associação é pouco satisfatória. (TUBERTJEANNIN et al., 2003)

De acordo com Jokovic e Locker (1997), uma das razões para a fraca associação entre o clínico e a autoavaliação deve-se ao fato de que muitas das doenças detectadas no ato do exame clínico são assintomática e provavelmente não são percebidas pelos indivíduos.

Para Benedetti; Melo; Gonçalves (2007), a saúde é um estado percebido de forma subjetiva e a fidedignidade da autopercepção não deve ter associação ou ausência dos indicadores clínicos.

Rocha; Goes (2008), afirmaram que a percepção é um conceito muito mais de "saúde" do que de "morbidade", que é o alicerce das avaliações clínicas, e, portanto, é necessário reconhecer que medidas de saúde e medidas de doenças são qualitativamente diferentes e têm implicações diferentes.

Outros relatos na literatura sobre autopercepção já mostrou que a maioria das pessoas vê sua condição bucal de maneira satisfatória, mesmo com a incompatibilidade clínica, uma justificativa pra esse fato é que as medidas clínicas de saúde utilizadas pelo profissional são superficiais não presumindo a saúde bucal das pessoas.

\section{CONCLUSÕES}

De acordo com os resultados obtidos e análises realizadas neste estudo, concluiu-se que os usuários que frequentaram o Restaurante Popular na cidade de Patos-PB fizeram uma avaliação positiva de sua condição bucal.
Indica-se o desenvolvimento de futuros estudos que envolvam etapas clínicas com a finalidade de subsidiar dados para estabelecer comparação entre os dados subjetivos da autopercepção com os achados clínicos.

Além disso, observa-se a necessidade de uma estratégia preventivo-interceptativa, voltada para esse grupo com o objetivo de consolidar seus conceitos e percepção sobre saúde bucal, e a compreensão de que esta reflete na saúde geral.

\section{REFERÊNCIAS}

ABEGG, C. Hábitos de higiene bucal de adultos porto-alegrenses. Revista Saúde Pública, v.31, n.6, p. 586-93, Dez, 1997. Disponível em: < http://www.scielo.br/pdf/rsp/v31n6/2333.pdf >>. Acesso em: 19/01/2018.

AQUILANTE, A.G.; ALMEIDA, B. S. D.; CASTRO, R.F.M.D.; XAVIER, C.R.G.; PERES, S. H. C. S.; BASTOS, J. R. D. M. A importância da educação em saúde bucal para pré-escolares. Revista de Odontologia da UNESP, v.32, n.1, p.39-45, Jan, 2003. Disponível

em<http://www.revodontolunesp.com.br/ed/58801720 7f8c9d0a098b4586 >. Acesso em: 19/01/2018

ARAÚJO, F.A.L.V.; ALMEIDA, M. I.; BASTOS, V. C. Aspectos alimentares e nutricionais dos usuários do "Restaurante popular Mesa do Povo". Saúde e Sociedade. v, 16, n.1, p.117-133, Jan-Abr, 2007. Disponível em : < http://bit.ly/2FUOlwD>. Acesso 19/01/2018. ARAÚJO, C.S.; LIMA, R.C.; PERES M.A.;

BARROS, A.J. Utilização de serviços odontológicos e fatores associados; um estudo de base populacional no Sul do Brasil. Cad Saúde Pública. v. 25, n.5, p.106379, Mai, 2009. Disponível em: < http://www.scielo.br/pdf/csp/v25n5/13.pdf >.

BALDANI, M.H.; BRITO, W.H.; LAWDER, J.A.C.; MENDES, Y.B.E.; SILVA, F.F.M.; ANTUNES,

J.L.F. Determinantes da utilização de serviços odontológicos por adultos e idosos de baixa renda. Revista Brasileira Epidemiologia. v.13, n.1, p.150-62 , Mar, 2010. Disponível em: < http://bit.ly/2EWfttJ > Acesso em: 19/01/2018.

BASTOS, J. R.M.; SALIBA, N.A.; UNFER, B. Considerações a respeito de saúde bucal e classes sociais. Revista Paulista de Odontologia, v. 18, n.4, p.38-42, 
Jul - Ago, 1996. Disponível em: <

http://saudepublica.bvs.br/pesquisa/resource/pt/bbo13696>. Acesso em: 19/01/2018.

BENEDETTI, T. R. B.; MELLO, A. L. S. F. D.; GONÇALVES, L. H. T. Idosos de Florianópolis: autopercepção das condições de saúde bucal e utilização de serviços odontológicos. Ciência \& Saúde Coletiva, v.12, n. 6, p.1683-1690. 2007. Disponível em: < http://www.scielo.br/pdf/csc/v12n6/v12n6a27.pdf>. Acesso em : 19/01/2018

BORTOLI, D.; LOCATELLI, F. A.; FADEL, C. B.; BALDANI, M. H. Associação entre percepção de saúde bucal e indicadores clínicos e subjetivos: estudo em adultos de um grupo de educação continuada da terceira idade. Publicatio UEPG: Ciências Biológicas e da Saúde, v.9, n.3. p.55-65, Set-Dez. 2003. Disponível em<

file:///C:/Windows/system32/config/systemprofile/Do wnloads/370-1171-1-PB\%20(1).pdf>. Acesso em: $19 / 01 / 2018$.

BUSATO, C.A.; CAVAZZOLA, A. S., ORTEGA, A.D.O.L., GUARÉ, O. R., NETO, A. S. Utilização do hipoclorito de sódio na descontaminação de escovas dentais: estudo in vitro. Revista de Odontologia da UNESP, v. 44, n. 6, p.335-339, 2015. Disponível em: < http://www.scielo.br/pdf/rounesp/2015nahead/18072577-rounesp-1807-257704214.pdf > . Acesso em: $19 / 01 / 2018$.

CARVALHO, C.; MANSO, A. C.; ESCOVAL, A., SALVADO, F.; NUNES, C. Self-Perception of oral health in older adults from an urban population in Lisbon, Portugal. Revista de Saúde Pública, v.50, p.1-8, 2016. Disponível em<

https://www.ncbi.nlm.nih.gov/pmc/articles/PMC49888 00/pdf/0034-8910-rsp-S1518-

87872016050006311.pdf> Acesso em: 19/01/2018.

COHEN, J. Statistical power analysis for the behavioral sciences. Hillsdale, NJ: Erlbaum, 2 ed. 1988.

GAIÃO, L. R.; ALMEIDA, M.E.L.; HEUKELBACH, J. Perfil epidemiológico da cárie dentária, doença periodontal, uso e necessidade de prótese em idosos residentes em uma instituição na cidade de Fortaleza, Ceará. Revista Brasileira de Epidemiologia, v. 8, n. 3, p. 316-23, Set, 2005. Disponível em <

http://www.scielo.br/scielo.php?script=sci_arttext\&pi $\mathrm{d}=\mathrm{S} 1415-790 \mathrm{X} 2005000300013>$. Acesso em: $19 / 01 / 2018$.

GOBATO, R.C., PANIGASSI, G., VILLALBA, J.P. Identificação do perfil de usuários de um Restaurante Popular do Município de Campinas. Revista Segurança Alimentar e Nutricional v. 17, p.14-25, 2010. Disponível em < https://periodicos.sbu.unicamp.br/ojs/index.php/san/ar ticle/view/8634789/2708>. Acesso em: 19/01/2018.
JOKOVIC, A.; LOCKER D. Dissatisfaction with oral health statusin an older adult population. J Public Health Dent, v.57, n.1, p.40-47. Jan, 1997. Disponível em<http://onlinelibrary.wiley.com/doi/10.1111/j.1752 -7325.1997.tb02471.x/full>. Acesso em: 19/01/2018.

LAKATOS, E.M.; MARCONI, M.A. Fundamentos da metodologia científica. In: Técnicas de pesquisa Altas, p.174-213, 2003.

LÖE, H.; THEILADE, E.; JENSEN, S.B. Experimental gingivitis in man. J Periodontol v.36, p177-87, Mai, 1965. Disponível em <

https://www.ncbi.nlm.nih.gov/pubmed/14296927> Acesso em: 19/01/2018.

MOURA, M. S.; CARVALHO, C. J.; AMORIM, J. T. C.; MARQUES, M. F. S. S.; MOURA, L. F. A. D.; MENDES, R.F. Perfil e práticas de saúde bucal do agente comunitário de saúde em municípios piauienses de pequeno porte. Ciência \& Saúde Coletiva, v. 15, n.1, p.1487-95, 2010. Disponível em:< http://www.scielo.br/pdf/csc/v15s1/061.pdf >. Acesso em: 19/01/2018

OLYMPIO, K.P.K.; BARDAL, P.A.P.; HENRIQUES, J.F.C.; BASTOS, J.R.D.M. Prevenção de cárie dentária e doença periodontal em Ortodontia: uma necessidade imprescindível. Revista Dental Press Ortodontia Ortopedia Facial, v. 11, n.2, p.110-9, Mar, 2006. Disponível em:<

http://www.scielo.br/pdf/csc/v15s1/061.pdf >. Acesso em: 19/01/2018.

PINHEIRO, H. H. C.; CARDOSO, D.G.; ARAÚJO, M.V.A.; ARAÚJO, M.C. Avaliação do nível de conhecimento sobre saúde bucal dos professores da Creche Sorena, Belém, Pará. Journal of Health Sciences. v. 23, n. 4, p. 297-303, Out, 2005. Disponível em < https://www.unip.br/presencial/comunicacao/publicac oes/ics/edicoes/2005/04_out_dez/V23_N4_2005_p29 7-304.pdf>. Acesso em: 20/01/2018.

REISINE, S. T.; BAILIT, H. L. Clinical oral health status and adult perceptions of oral health. Social Science \& Medicine. Part A: Medical Psychology \& Medical Sociology, v. 14, n. 6, p. 597-605, 1980. Disponível em <

https://www.ncbi.nlm.nih.gov/pubmed/7209633>. Acesso: 20/01/2018.

ROCHA, R. A. C. P.; GOES, P. S. A. D. Comparação do acesso aos serviços de saúde bucal em áreas cobertas e não cobertas pela Estratégia Saúde da Família em Campina Grande, Paraíba, Brasil. Caderno de Saúde Pública, v. 24, n.12, p. 2871-80, Dez, 2008. Disponível em <http://www.scielo.br/scielo.php?pid=S1413$81232010000700061 \&$ script=sci_abstract\&tlng=pt $>$. Acesso em: 20/01/2018. 
SANTOS, F. B., MORAIS, M. B., SOUZA B. A., SAMPAIO, F. C., FORTE, F. D. S. Autopercepção em saúde bucal de idosos em unidades de saúde da família do Distrito Sanitário III de João PessoaPB. Arquivos em odontologia, v. 43, n.2, p.23-31, Jun, 2007. Disponível em<

https://seer.ufmg.br/index.php/arquivosemodontologia /article/view/1512/1079> . Acesso em: 20/01/2018.

SANTOS, P. A.; RODRIGUES, J. D. A.; GARCIA, P. P. Conhecimento sobre prevenção de cárie e doença periodontal e comportamento de higiene bucal de professores de ensino fundamental. Brazilian Dental Science, v.6, n.1, p. 67-70, 2010. Disponível em:< http://ojs.fosjc.unesp.br/index.php/cob/article/viewFile /10/574>. Acesso em: 20/01/2018.

TEIXEIRA, M. B.; CASANOVA, A.; OLIVEIRA, C. C. M. D., ENSGTROM, E. M.; BODSTEIN, R. C. D. A. Avaliação das práticas de promoção da saúde: um olhar das equipes participantes do Programa Nacional de Melhoria do Acesso e da Qualidade da Atenção Básica. Saúde debate, v.38, p. 52-68, Out, 2014. Disponível em< http://www.scielo.br/pdf/sdeb/v38nspe/0103-1104sdeb-38-spe-0052.pdf>. Acesso em: 20/01/2018.

TUBERT-JEANNIN, S.; RIORDAN, P.J.; MORELPAPERNOT, A.; SABY-COLLET, S. Validation of an oral health quality of life index (GOHAI) in France. Community Dent Oral Epidemiol, v.31, p. 275-84.

Aug, 2003. Disponível em <

https://www.ncbi.nlm.nih.gov/pubmed/12846850>

Acesso em: 20/01/2018.

\begin{tabular}{l}
\hline José Klidenberg de Oliveira Júnior \\
Mestre em Ciências Odontológicas pela Universidade \\
Federal da Paraíba. \\
\hline Luiz Eduardo Marinho Vieira \\
Mestrando em Clínicas Odontológicas pela \\
Universidade Estadual da Paraíba \\
\hline Manoela Natacha de Almeida Silva \\
Especialização em Ortodontia Centro Caririense de \\
Pós-Graduação \\
\hline Mariana Gil Gomes de Medeiros Araújo \\
Pós-graduanda em Ortodontia pelo Centro de \\
Odontológico de Estudos e Pesquisas - COESP \\
\hline Mayara da Silva Henriques Limeira \\
Especialização em Ortodontia pelo Instituto \\
Paraibano de Estudos Odontológicos - IPEO \\
\hline Dayse Hanna Maia Oliveira \\
Universidade Federal de Campina Grande. \\
\hline
\end{tabular}

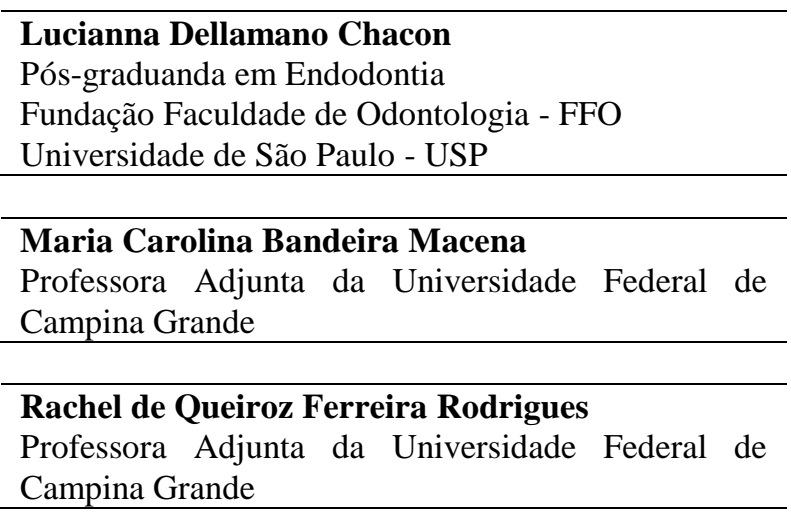

